\title{
The Ideas and Methods: Realization of Modern Artists of Kazakhstan in Creative Works through Colour Distribution of Paintings - Muratbayev
}

\author{
Bolisabev D, Kunzhigitova G* and Burkitbayev T
}

Pedagogical Science, M. Auezov South Kazakhsthan University, Kazakhsthan

\begin{abstract}
The article features color combination and painting techniques of the Kazakh artists, such as Muratbayev, Muratbayev, Bube Belly, Akzhan Fbdieva and Nartay Zhardemov. Realization of color combinations can be accomplished through the following way: all of creative works/images, which come together in tone and color correlations, are proportional to visual image; the main integrity of fine art works is only the image in the soul of the artist - "work in soul". The main part of Art works/paintings is being in harmony within themselves. Hence, the artists of modern era in Kazakhstan have been able to use harmony techniques in their art works. A person is in harmony with nature. It can be seen from mountain shapes, valleys, trees and grasses, animals and birds, which are perceptive to human brain and human eyes. Crucial factors have been rhythm and symmetry, the eternal harmony of creators. The universal manifestation of rhythm and symmetry leads to single order of all that are present in nature.

$21^{\text {st }}$ century's Art of Independent Kazakhstan is expressed through aesthetics, language, implements of the high visual art. Art of Independent Kazakhstan is covering continuity of cultural, political, historical signs of the modern art. Therefore, paintings of Independent Kazakhstan are unique in their structure. They have been developed for 25 years in correlation with other art forms, improving the new directions, as well as forms and genres. The art works and paintings of Independent Kazakhstan form their own aesthetic language, specific modern methods, national traditions and particular art language of the graphic works, as well as the new directions of Kazakhstan's paintings that have resulted from certain specific factors. That is why it is important to understand the main directions of Visual Art of Independent Kazakhstan's artists, along with the color combination and painting techniques that they have used. Hence, that is what this paper is addressing.
\end{abstract}

Keywords: Color score; Resource of visual arts; Process of realization artistic design; Different technique; Imagination; Kazakh artists; Image; Creative

\section{Introduction}

Art is an important component of art life in society, and valuable and axiological basis of art was developed by Ananyev B. The modern culture develops under postmodernism sign, at the same time developing cross-disciplinary problems, which are already available in a modernism world. Nowadays art represents different alternatives to the traditional ways with which an image appeared, as well as mentalities and valuable hierarchy, that are cultural and historical phenomenon, steaming from a person's feelings in the end of XX century. Roganova [1] explained that moreover, art is the core of art life that reflects a cultural phenomena and lifestyle of modern society, developing in a paradigm and allowing to consider sociocultural process as an interaction between traditions and innovations, as well as elements of enduring and passing culture to future generation [2]. The background of the given research is to investigate Kazakhstani paintings, focusing on positive influence of Republic's independence and its impact on high-quality creative minds of modern artists. Since the independence years, Kazakhstan's artists have begun to rethink the creativity directions, which have been emerging into fine arts' areas in Kazakhstan, such as symbolic, explained by conceptual Ozhegov and Shvedova [3]. The art of modern Kazakhstan differs from the traditional art forms, and it can be characterized as a creative search, rejection of traditional stereotypes, development of new styles in drawing images, which perfectly interpret the issues in the modern era. Kazakh nations' customs and history, the way of life among Kazakh people have become a characteristic feature of all modern paintings in Kazakhstan. The memory, therefore, expresses the national history, a chain of its events, legends/myths about the heroes, also including scenes of everyday life among the generations in great Kazakh steppe.
National cultural memory is perceived as a specific to an ethnic community, leads our culture to a new round of self-knowledge, to a philosophical, intellectual, conscious understanding of its own self, its spiritual contribution to universal human culture's treasury. The main idea of the research consists of general analysis of art ideas and art works of modern Kazakhstan's artists through evaluating viewers' perceptions of the following artists' some art works: Bube Nellie Vitalyevna, Akzhan Abdiyeva, Nurtaya Zhardemov and Abduakhat Muratbayev. Uniqueness of the research is combination of several methods of a research in science field and publication of achievements of wide audience. During creating a painting or art work, an artist usually divides a sketch into five sections: vertical and horizontal, and starts his/her with an imaginary picture. The geometrical analysis of organizing art work's perspective should follow visual perception laws; and proportioning of the art work/painting is required in art work's classical analysis, which is necessary to understand architectonic paintings. In addition, harmony can be defined as a pleasing arrangement of parts, whether it is music, poetry, color, or even an ice cream sundae. In visual perception experiences, harmony is something

*Corresponding author: Kunzhigitova G, Candidate of Pedagogical Science, M. Auezov South Kazakhsthan University, Kazakhsthan, Tel+ 7-87056885749; E-mail: talgat.62@inbox.ru

Received August 11, 2017; Accepted August 16, 2017; Published August 22, 2017

Citation: Bolisabev D, Kunzhigitova G, Burkitbayev T (2017) The Ideas and Methods: Realization of Modern Artists of Kazakhstan in Creative Works through Colour Distribution of Paintings - Muratbayev. Arts Social Sci J 8: 294. doi: 10.4172/2151-6200.1000294

Copyright: (c) 2017 Bolisabev D, et al. This is an open-access article distributed under the terms of the Creative Commons Attribution License, which permits unrestricted use, distribution, and reproduction in any medium, provided the original author and source are credited. 
that will be pleasing to eyes. Harmony engages a viewer and creates an inner sense of order, and a balance in the visual experience. Therefore, when something is not harmonious, it's either boring or chaotic. An extreme situation in a visual experience of such non-harmonious art work is that a viewer is not engaged. The human brain usually rejects under-stimulating information. And other extreme example is a visual experience that is so overdone, so chaotic that the viewer can't stand to look at it. The human brain also rejects what it does not organize, what it does not understand. Hence, the visual perception task requires that we present a logical structure of art work or paintings, so that the work is understandable for the viewer and pleasant to look at.

\section{Methodology}

The research based on an analytical analysis of artistic along with artistic pictorial phenomenon, and systematization of informational knowledge. An important aspect of this method is an integral part, and its objective requirements exclude results' subjective interpretation. The systematization of observations will ensure that all collected data and research results are accessible to other scientists. The structure of this method contains several independent components:

- A conceptual component - a concept of an object's form under study - in this study the artist's picturesque and creative works are performed using various techniques;

- An operational component - the principles governing the cognitive activity of the subject - analytical;

- Critical;

- Reflection - scientific and analytical activity that is aimed on studying a socio-economic phenomenon of the Republic of Kazakhstan, and their impact on analytical knowledge;

- Abstract - concepts that arose in the research process in order to deepen study (abstract concepts such as color, tone, beauty, harmony of the image, etc.);

- Synthesis - the unification of the results and data, obtained in analysis, allowing to expand knowledge, to construct new one.

\section{Results}

The ideas and methods' of research used in the artwork analysis in pedagogy and the importance of each feature.

\section{Color distribution of Muratbayev's paintings}

The harmonization principles between the colors are similar to the principles of tones in music, R. Arnheim Arnheim, [4] argued that harmony arises when color range is based on color scheme. In turn, color schemes are formed via brightness and saturation of colors that gradually change from the lowest degree of these qualities to the highest. Color solution in Abduahata Muratbayev's works is based on colors' harmony, which is based on their unity and change, organization and randomness, balance and imbalance. Mr. Abduahata's color scheme in his works has common elements, where the color system "brings" the impression of unity. The color harmony is not only a sense of unity, instead, it is born from a dynamic relationship between unity of color elements and their internal changes. The color harmony is the most important thing of artistic expression in painting, along with the composition, drawing, perspective, light and shade, texture. Drawing a diagonal line allows the painter to locate a geometric center of the canvas, as well as to locate the movement of forms on the diagonal directions. The division of paintings into five parts in height and width shows that the main figure is located on the golden section line (2:3). The separation pattern through the vertical line shows that a bottom (two parts) occupies horizontal surface, whereas a top (three parts) occupies the perspective image. The left part of the picture is an entering part, where a viewer can see several shapes of the people. The central part, the main group of characters in the painting, occupies two parts. In the fourth part of the painting, viewer's eyes is able to catch the depth of the perspective. It unfolds the story of the ancient city. There is a smooth transfer into the fifth part of the painting, with the symbols and petroglyphs. However, the viewer's sight will not stay here long, since the main figure of the picture, the loaded wagon, attracts the viewer's attention. The strongest contrast of tone and color, as well as contrast of movement are emphasized in here. According to the wellknown psychophysical law of Weber-Fechner, it is known that in the perception of differences between the two object images, the absolute level of brightness is not as important as their proportional relationship. Therefore, although the lightness of white versus black paint is 2530 times, this range can be expressed in any ratio of brightness. This brightness ratio was successfully used in a reduced scale lightness in Mr. A. Muratbayev's paintings. The author has been able to properly organize and construct the paintings, transferring tonal and color relationships, proportional to the visual image. Bright paintings, made in the Kazakh Patchwork style, bring artistic atmosphere and mood of kazakh folk festival to the surrounding. Muratbayev's paintings are different from national art in their identity and specificity. Artchives, [5] explained about that is because, Mr. Abduahat's art is different from the fellow members' in the national philosophy; these art works are hidden in symbolic images and details, and manifested through plastic sophisticated ornamental forms and expressed in decoration. Each picture is a kind of pictorial puzzle, where the secret that was clear to our predecessors, was encoded. Author has shaped individual architectural language that speaks to contemporary artists' perception. The texture of paintings is the illusion of hand-weaving, that is accepted as tapestries. Additionally, in one of his styles, Mr. Muratbayev has embodied a variety of plastic solutions that encourage viewers to follow the author's fantasy game: whether it is a realistic solution of human image or contingent, paintings, decorative objects, images of elders and elderly couples' achieved an amazing integrity and credibility of the transmission. The artist often uses either achromatic or light contrasts. The essence of using these techniques is that a bright spot on a dark background seems lighter, and inversely, dark on a light background seems darker than it really is. This bright (or dark) spot (which is also responsive to the field) changes the lightness, so that it is more noticeable than the surrounding's background. A simultaneous light contrast effect diminishes at extremely high brightness. Additionally, at a very low or high contrast, the difference in brightness is negligible or absent [6]. Simultaneous light contrast depends on an area size of matched tones. The less reactive the field, the more the field lightens. Contrast also depends on the reacting field's configuration (a circle, a ring, a square are on the same background and on the same lighting conditions, and they are accompanied with contrast of varying strengths). The contrast's strength decreases with increasing distance between the contrasting fields. The contrast is evident not only in the darkening or lightening of reacting fields, but also in changing their sizes. A bright spot on a dark background seems bigger than it actually is, and vice versa, a dark spot on a light background seems smaller [7]. Overall, energy of Mr. Muratbayev's paintings and art works has the positive impact on the audience. The plot of the paintings also has a deep meaning, every detail of the picture is important and has its meaning. In the artist's works, the Kazakh national images 
Citation: Bolisabev D, Kunzhigitova G, Burkitbayev T (2017) The Ideas and Methods: Realization of Modern Artists of Kazakhstan in Creative Works through Colour Distribution of Paintings - Muratbayev. Arts Social Sci J 8: 294. doi: 10.4172/2151-6200.1000294

Page 3 of 6

harmoniously correspond with modernism, consonance criteria; and images are in agreement within each other, and opposed to chaos.

The ideas and methods' that have been realized by modern artists of Kazakhstan

Harmony is a philosophical and aesthetic category, signifying a "high level of order diversity, the optimum Harmonies in differences is the whole system, meets the aesthetic criteria of perfection and beauty", i.e. Harmony, as it was mentioned earlier, is a set of similarities and differences, combined in a specific ratio; harmony is a concept of integrity and perfect organization of an aesthetic object, that arises through qualitative and quantitative differences and interaction between the elements. Overall, harmony is a system, a set of different and general things, which are combined in a certain ratio (Figures 1-6). According to Zaizev [8], color harmony is pleasing to eyes, it is

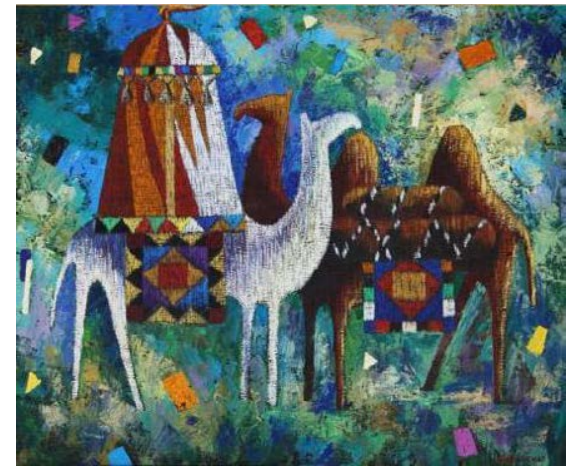

Figure 1: Expectation.

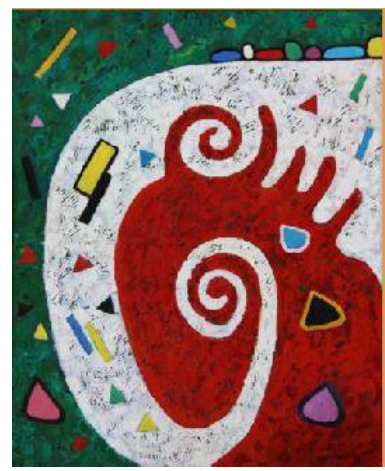

Figure 2: Immortal life.

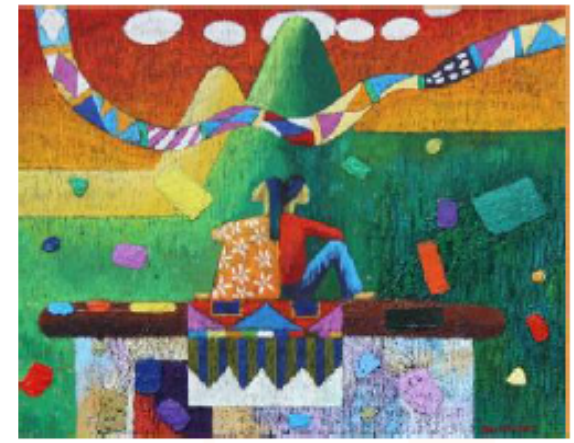

Figure 3: The Two.

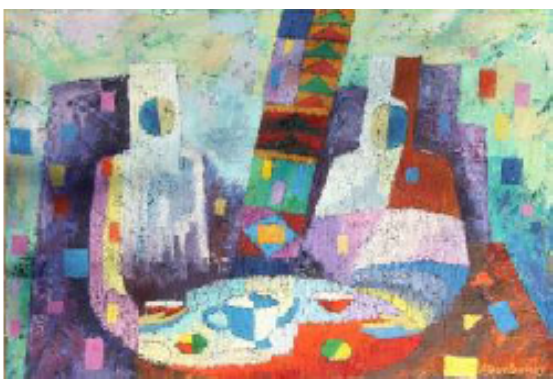

Figure 4: The after noon tea.

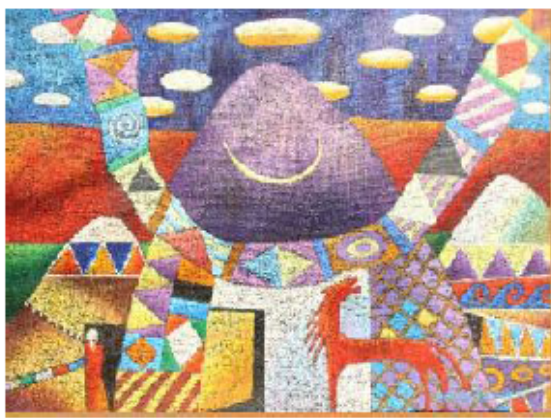

Figure 5: The Moon in the Night.

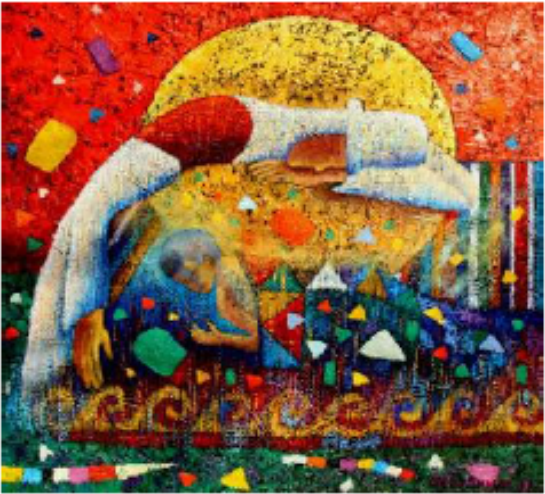

Figure 6: Lullaby.

a beautiful combination of colors, suggesting some consistency, order and proportionality among them. It is also noted by the author that the main characteristics of color may act together in different links forming different harmonious combination, and offering basic variations for lightness, saturation and brightness. The painting's proportions reflect perfect math, such as symmetry of elements, repetition of equal and alternating values of the golden section in order to create sensuously perceptible rhythm for the painting. The artist plans to affect a viewer via selecting the particular tools in his paintings. The golden proportion is a kind of symmetry (gold symmetry), and it is included in general mathematical symmetry relations. Paintings, in which the focus is at the geometric center of the canvas, are not considered as asymmetric. They are symmetrical, but it is a special kind of symmetry, it is symmetry of gold. Overall, this symmetry and proportioning systems give the artist a self-examination tool, in order to check what is made intuitively and through feelings. A series of pictures by Nelly Bube Vitalievna are dedicated to the Great Silk Road. The author's 
technique combines painting, drawing, collage and glaze. Ms. Bube's works are light colors, filled with warmth and serenity. In addition, in his art works, we can also see the texture of the clothes, nature, and even sunlight. Ms. Akzhan Abdieva's paintings have lightness and revelations' themes. Ms. Abdieva's art works describe everyday life scenes, the usual and ordinary parts of life. There are also moments of quiet joy and unity in her paintings. All components of the image and expression of the artist's ideas; including decorative filling patterns, light and color tones' composition, as well as color development all of them are organically consistent with each other. The paintings of the author, expressing the content, are holistic phenomena and are easily perceived by the spectator. There is a dominant spotlight centre in Ms. Akzhan Abdieva's paintings. From visual perception law and unity of the image's view, the dominant centre is the right direction in organizing and constructing a picture. A viewer looks at only one center, the thing that attracts attention most. Next, the eyes (of the viewer) lie on colorful spots, which lead him/her to other places of the picture. This specific viewing order is provided by the artist herself, in her painting's organization. The viewer sees all the small details, understanding deeper meaning of the paintings with the aid of small details, and his/her eyes again return to the main content. Mr. Nartai Zhardemov is one of the talented young artists of Independent Kazakhstan, and he works on surrealism art, where music and visual arts are closely combined. In the recent years, the artist has created many unique works/paintings, particularly focusing on Kazakh and foreign ideas. The artist's professionalism is expressed in a realistic painting of life, where he used multiple color paints, and "accompanied" the chosen subject. All particular skills are gathered into a single harmonious and coherent system, as it is operated by a musical "director" of an orchestra in order to create a holistic harmony for expressing creative ideas. Perfect forms are created by another artist. Mr. Nartai Zhardemov feels his own ideas and determines the format, including canvas size, positions it. Next, he concentrates the canvas to the right place for a full expression of ideas, then without breaking the chosen idea rhythm. This can be seen in "Ak Erke, Akzhayik", "Three Ages of Love" paintings of Mr. Nartai Zhardemov, where all elements are intended to express the idea in a smooth and rhythmic style. Love to nature, imagination play, rigorous calculations of proportions and intervals (in which the author defines the format), they all can influence the nature of rhythm. Rhythm is a regular alternation of comparable and sensually tangible elements (Fine art elements). Symmetry is a special case of the rhythm. As a consequence, a number of combinations can be built: the golden proportion and a symmetry; a symmetry and a special rhythm; hence, the rhythm is everywhere and permeates everything. Artist Nartai's paintings, their contents and his ideas are associated with the painting's format, rhythm, symmetry, and a golden section. Rhythm is moving part of the painting, and it makes the painting alive. The dynamic symmetry of the golden ratio creates a sense of movement, telling its story with proportional intervals. Light deviations come from the strict symmetry, rhythm, as well as contrasts of light and dark, large and small, the harmony of colors (Figures 7 and 8 ). There would be no rhythm without pauses in music. The artist arranges paintings, removing all unnecessary details. Also, an artist creates an artistic environment in the painting, which contributes to fulfillment of the plan. The format of "Three Ages of Love", painting by Mr. Zhardemov N., is close to rectangle of the golden section (Figure 6). An old man's figure is in the middle of the canvas. The distance from the right edge of the painting till the old man's head, and the distance from the middle to the left edge of the picture, both of these distances make triple a proportion of the golden section. There are different areas are shown in the painting: on the one hand, the artist's ability

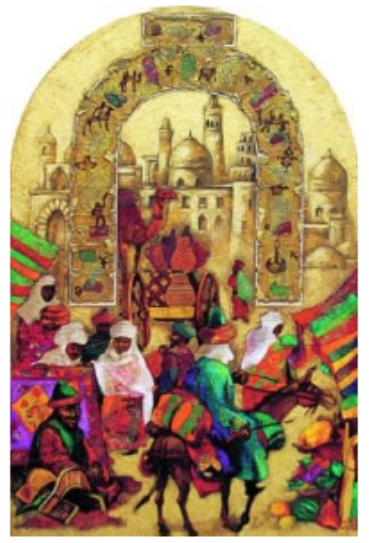

Figure 7: Mellu Bue.

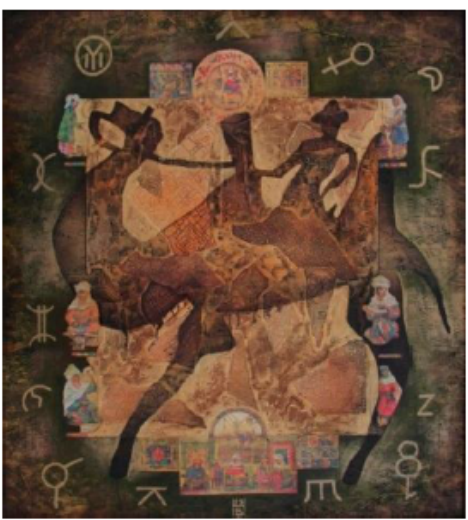

Figure 8: Nelly Bube.

to subordinate laws and to detect painting's content, and on the other hand, his ability to subordinate the laws of visual perception. When the life's rhythm and the artist's beating heart can be transmitted from the painting, the viewer perceives the painting as something close to him/ her. Therefore, a viewer experiences a sense of recognition, joy, union with miracle painting, and admires artist's painting skills (Figures 9-13). Nothing can develop the imagination like poetry. Nothing can develop a sense of rhythm as music. Without the imagination and sense of rhythm, there will be no great artist. The rhythm of one's own time, of own age or rhythm of past periods can be only felt and realized. Without such a sensory awareness, an artist is not able to express it.

\section{Conclusion}

The given study demonstrates that the paintings have the highest idea that cannot be replaced by anything. It can be also understood that a painting is a poem without words. LiveJournal, [9] focussed Whether an artist builds a painting either in direct or in reverse perspective, whether the painting has real or unreal plot, all of them are not restricted to one or another. However, compositional and rhythmic structure of the painting are supposed to be carried according to proportions of the golden section (descending height or width number patterns), then there are always a new sense and image's perception. Due to the brain and eyes' structure, one always sees symmetrical composition and colorful rhythms and proportions of the golden symmetry, meaning they are in harmony with each other. Durer said: “... the art lies in the nature; who will be able to pull art out of it, then he/she owns 


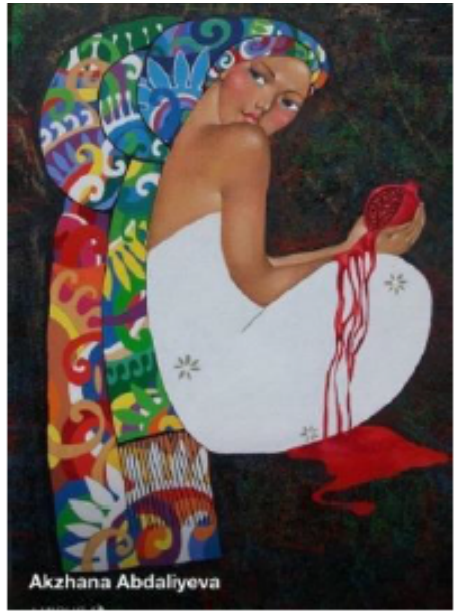

Figure 9: Pomegranate.

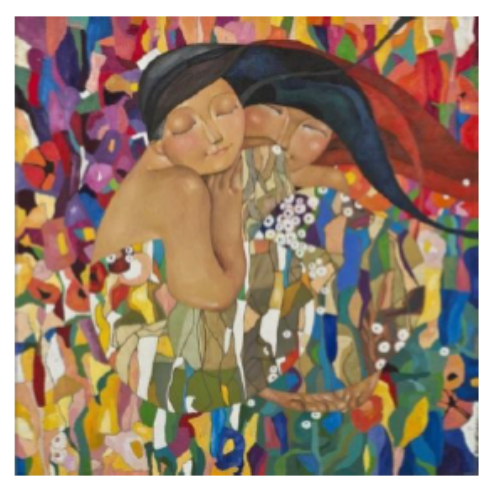

Figure 10: Girl Friend.

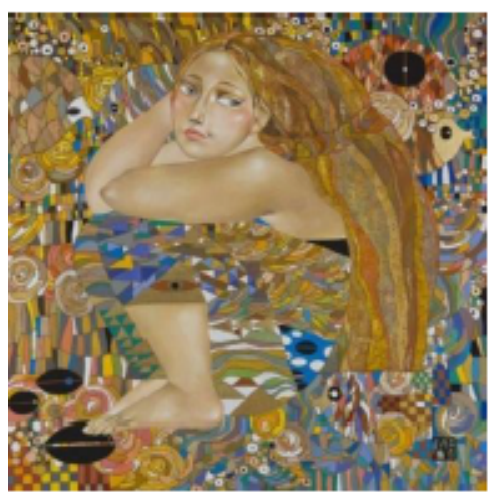

Figure 11: Tenderness.

it". Kile, [10] explained the Creativity of young and famous painters harmoniously coexists with modern painting and traditional classical art methods. Many elements of traditional Kazakh and traditional classic arts form new artistic directions. These new directions preserve the continuity of traditional approaches and contemporary art methods, thus, developing it in a new rhythm. Modern directions of painting in Kazakhstan expanded the subject, enriched an artistic language, and contributed to national values' and spirituality search. Additionally, modern paintings have formed a unique language, which

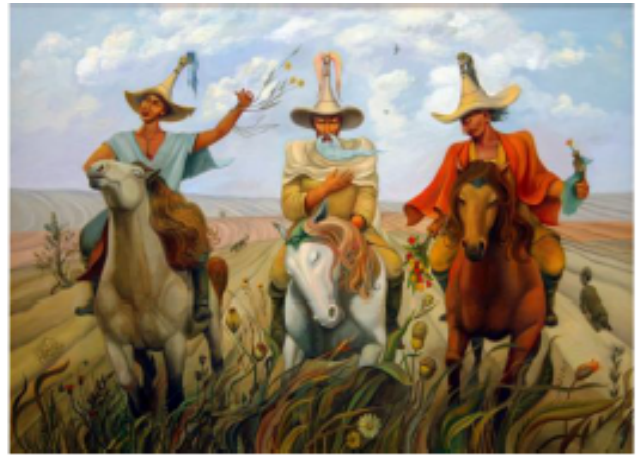

Figure 12: Three ages of Love.

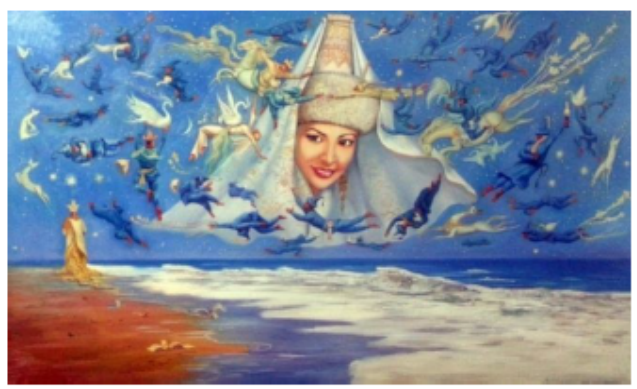

Figure 13: Ak Erke, Akzhayik.

is different from the arts' language of other nationalities, also they have opened the tendencies that are based on national understanding of the world. Esmakhanov [11] in modern art, national themes, traditional rituals, concepts and myths are treated in a new way. Modern paintings of Kazakhstan differ from European continuity, as well as from traditional arts in a variety ways; including, unprecedented dynamics of originality and development (obtained during state's independence years), freedom of artists' creative expression; diverse, wide vector of directions and searches based on national traditions and experience of modern world art. Contemporary fine art of Kazakhstan is in continuous turbulent movement, in continuous process of creative experiment. There is coexistence of various manners and styles, plastic and pictorial approaches to the world, from opposing each other to differing only in the subtle nuances in the worldview. Therefore, the fundamentals of Kazakhstan's paintings in 21st century come from heritage and experience of national art and the achievements of world art. In the late XX and early XXI century, a special place has been occupied by innovative concepts and media technologies in Fine arts' arena of Kazakhstan [12]. These sectors express socially aggravated thought in a new form into the modern context of ancient traditions. To sum up, XXI century's paintings of Kazakhstan can be understood as the art of a new visual perception. This art type seeks to reveal the objects' essence, entity that are based on an intellectual sensation. At the same time, the modern art of Kazakhstan constructs artistic language and images, which is distinguished by the artistic awareness of this or that era.

\section{References}

1. Roganova I (2010) Updating paradigm of post-modernism in culture of the end of the XX century. (Thesis of candidate dissertation of culturology doctor). The Capital Institute of Foreign Languages, RF.

2. Shirshin I (1980) Dynamics of culture - Minsk: BGU publishing house. 
Citation: Bolisabev D, Kunzhigitova G, Burkitbayev T (2017) The Ideas and Methods: Realization of Modern Artists of Kazakhstan in Creative Works through Colour Distribution of Paintings - Muratbayev. Arts Social Sci J 8: 294. doi: 10.4172/2151-6200.1000294

Page 6 of 6

3. Ozhegov SI, Shvedova NY (1992) Explanatory dictionary of Ozhegov.

4. Arnheim R (1974) Art and Visual Perception Education. Moscow In-text reference.

5. Artchives: blog of the project (2017) A social network for artists unites contemporary artists, galleries and connoisseurs of painting. In-text reference.

6. Abisheva SI (2009) Color management: a textbook for students of higher educational institutions, p: 116.

7. Abisheva SI (2007) Formation of harmonious color perception in classes of color management for initial courses students of the architectural and design faculty. Omsk State Pedagogical University, RF.
8. Zaizev AS (1986) The science of color and painting education.

9. LiveJournal Inc (2015) Modern painting of artists of Kazakhstan: kovlam LiveJournal, LiveJournal, Inc.

10. Kile Peter (2007) Albrecht Durer. Kile Peter.

11. Esmakhanov A (1998) Contemporary fine art of Kazakhstan. Causes and conditions. Cultural Monuments of Kazakhstan: multi-volume series, p: 80.

12. Scientific Electronic Library, Cyberleninka Sigada D (2015) The main approaches of research of art in theoretical culturology. Scientific Electronic Library. 